\title{
Balık ve Balık Ürünlerinde Biyojen Aminler ve Önemi
}

\author{
Sena ÖZBAY-DOĞU ${ }^{1 *}$, Cemalettin SARIÇOBAN ${ }^{2}$ \\ ${ }^{1}$ Tuz Gölü Su ve Çevre Uygulama ve Araştırma Merkezi, ASÜÇEM, Aksaray \\ ${ }^{2}$ Selçuk Üniversitesi, Ziraat Fakültesi, Gıda Mühendisliği Bölümü, Konya
}

Geliş (Received): 12.03.2015

Kabul (Accepted): 23.08.2015

\begin{abstract}
ÖZET: Biyojen aminler, gidalarda bulunan serbest amino asitlerin dekarboksilasyonu sonucunda oluşan bileşiklerdir. Histamin, kadaverin, putresin, tiramin, spermin ve spermidin gıdalarda sıklıkla bulunan biyojen aminlerdir. Özellikle balık ve balık ürünleri, biyojen aminlerin oluşumu açısından büyük önem taşımaktadır. Bu gibi ürünlerde biyojen aminler mikrobiyal dekarboksilaz aktivite ile hızla oluşmaktadır. Yetersiz hijyen, kontaminasyon, hammaddenin mikrobiyal yükü ve sıcaklık gibi faktörler bu oluşumu hızlandırmaktadır. Balık ve ürünlerinin soğukta muhafazası ve işlenmesi, biyojen amin oluşumunun engellenmesinde en etkin yöntemlerdir. Bunun dışında, ışınlama, tuzlama, modifiye atmosferde paketleme ve vakum ambalajlama gibi uygulamalarla biyojen amin miktarı azaltılabilmektedir. Çalışmamızda balık ve balık ürünlerinde oluşan biyojen aminler, oluşum sebepleri ve önleme yolları ayrıntılı incelenmiştir.
\end{abstract}

Anahtar Kelimeler: Balık, balık ürünleri, biyojen amin, histamin, sağlık

\section{Biogenic Amines in Fish and Fish Products}

\begin{abstract}
Biogenic amines are compounds forming decarboxylation of free-amino acids in the food. Histamine, cadaverine, putrescine, tyramine, spermidine and spermine are biogenic amines that often found in food. In particular, fish and fish products have great importance in terms of formation of biogenic amines. Amount of biogenic amines is rapidly increasing with the microbial decarboxylase activity in these products. This formation is accelerated by various factors such as poor hygiene, contamination, microbial load of the raw materials and temperature. Cold storage and processing of fish and fish products are the most effective method to preventing the formation of biogenic amines. Furthermore, the amount of biogenic amine can be reduced by various methods such as irradiation, curing, modified atmosphere packaging and vacuum packaging. In this paper, biogenic amines that occur in fish and fish products, occurrence causes and methods of prevention of biogenic amines have been analyzed.
\end{abstract}

Key words: Fish, fish products, biogenic amine, histamine, health.

\section{GIRIŞ}

Biyojen aminler, doğal olarak gidalarda bulunan ya da bakteriyel veya gida kökenli enzimlerin farklı öncülleri dekarboksile etmesi sonucunda meydana gelmektedirler. Biyojen aminler, özellikle balık ürünleri ile ilişkilendirilmekte ve ürünün bozulması ile işleme ve depolama şartlarının hijyenik kalitesi açısından birer indikatör olarak da görülmektedir. Bu bağlamda biyojen aminler hem ürün kalitesi, hem de tüketici sağlı̆̆ açısından önem taşımaktadırlar. Sıcaklık, üretim koşullarında hijyeninin sağlanması ve hızlı ürün işleme, biyojen aminleri önlemede en hızlı ve etkin yöntemler olmaktadır. Bu temel yöntemlerin uygulanmasından sonra, farklı ürünleri işleme ya da farklı ambalajlama seçenekleri ile balık ve balık ürünlerindeki biyojen amin oluşumları kontrol altına alınabilmektedir.

\section{BIYYOJEN AMIN KAVRAMI ve OLUȘUM MEKANIZMASI}

Poliaminler, hücrelerde yaygın olarak bulunan ve nükleik asit ile membran yapısını da içeren pek çok hücre içi olayda yer alan hücre bileşenleri olarak tanımlanmaktadır (Kalac ve Krausova, 2005). Doğal poliaminler, poliamin biyosentezi ile oluşurken, biyojen aminler, serbest amino asitlerin bakteriyel dekarboksilasyon reaksiyonları sonucunda oluşmaktadır (Bardocz, 1995; Shalaby, 1996). Biyojen aminler, serbest aminoasitlerin, bakteriyel ve enzimatik dekarboksilasyonu (Erkan ve ark., 2006) veya aldehit ve ketonların aminasyonu veya transaminasyonu ile oluşan azotlu bileşikler olarak da tanımlanabilmektedir (Demirci, 2003).

Aminoasit dekarboksilaz, mikroorganizmalarda çoğunlukla bulunmasına rağmen, Lactobacillus, Pediococcusve Streptococcus gibi laktik asit bakterileri ile, Bacillus, Citrobacter, Clostridium, Klebsiella, Escherichia, Proteus, Pseudomonas, Salmonella, Shigella, Photobacterium gibi türler bir veya daha fazla aminoasidi dekarboksile etme yeteneğine sahip olmaktadırlar (Brink ve ark., 1990). Ayrica Enterobacteriaceae ve Pseudomonas, balığın doğal mikroflorasının bir parçası olarak da kabul edilmektedir (Paleologos ve ark., 2004).

Biyojen amin oluşumu, mikroorganizmaların, proteolitik ya da dekarboksilaz aktiviteleri, gelişim durumları ve bu süreçlerin birbiri ile etkileşimine göre değişen, karmaşık süreçlerden oluşmaktadır (Gardinia ve ark., 2001). Mikrobiyal gelişim ile yakından ilişkili olan biyojen amin oluşumu, aynı zamanda mikroorganizmaları etkileyen faktörlerden (sıcaklık, su 
aktivitesi, $\mathrm{pH}$ vb.) de etkilenmektedir. Bu sebepten, benzer hammaddeler, sicaklığın etkisiyle farklı seviyelerde biyojen amin içerebilmektedir (Zaman ve ark., 2009). Ancak spermin ve spermidin biyojen aminleri, gidalarda doğal olarak bulunmakta ve oluşumları bakteriyolojik bozulma ile ilişkilendirilmemektedir (Özoğul ve ark., 2002b).

G1dalarda bulunan farklı biyojen amin öncüllerinin dekarboksile edilmesi sonucunda farklı biyojen aminler oluşmaktadır. Örneğin histamin, histidinin, kadaverin ise lizinin dekarboksile edilmesi sonucunda meydana gelmektedir. Hammadde, biyojen aminlerin öncüllerini farklı kombinasyonlarda bulundurduğu için, biyojen aminin çeşidi ve miktarını belirleyen önemli bir faktör olmaktadır (Zaman ve ark., 2009). Bu şekilde, farklı mikroorganizmalar, farklı biyojen amin öncüllerini dekarboksile edebilmektedir. Örneğin Lactobacillus sp., FH (fakültatif hetero fermentatif), lizin ve ornitini dekarboksile ederek, sırasıyla kadaverin ve putresin oluştururken, Leuconostoc, tirosin ve histidini dekarboksile ederek, sirasiyla tiramin ve histamin oluşturabilmektedir (Dapkeviciusa ve ark., 2000). Histamin, tiramin, $\beta$-feniletilamin, triptamin, putresin, kadaverin, spermin ve spermidin gidalarda en sik karşılaşılan (Shalaby, 1996), tiramin ve histamin ise gidalarda bulunan bakteriyel orjinli en önemli biyojen aminler olmaktadır (Bover-Cida ve Holzapfel, 1999).

Biyojen aminler, bazı meyve ve sebzelerde de doğal olarak bulunmasının yanı sıra proteince zengin gidalarda, mikrobiyal aktivite sonucunda veya fermente gida ve içkilerde de oluşabilmektedir (Demirci, 2003). Zaten pek çok gıdada tüketildiklerinde kolaylıkla tolere edilebilir düzeylerde histamin bulunmaktadır (Shalaby, 1996) ancak biyojen aminler, peynir, balık, bira, şarap, çikolata, lahana turşusu ve bazı fermente gıdalarda (yoğurt gibi) yüksek seviyede görülebilmektedir (Bardocz, 1995). Özellikle balık ve balık ürünlerinde biyojen aminler, bozulmanın ve depolama sürecinde tazeliğin bir indikatörü (Hu ve ark., 2012) olarak değerlendirilmekte ayrıca farklı fizyolojik tehlikeleri barındırmakta (Stute ve ark., 2002; Erkan ve ark., 2006) ve teknolojik olarak önem taşımaktadır (Özoğul ve ark., 2004b).

Bunlara ek olarak gidalarda bulunan biyojen aminlerin tespitinde kullanilan temel metotlar, ince tabaka kromatografisi, siv1 kromatografi, gaz kromatografi, biyokimyasal analizler ve kapiler elektroforez temelli yöntemlerdir (Önal, 2007).

\section{Biyojen Amin Metabolizması ve Toksikolojik Etkileri}

Biyojen aminlerin yüksek miktarda alımları sonucunda toksik etki gösterdikleri bilinmektedir. Histamin zehirlenmesinin tüm dünyadaki en önemli sebebinin, yüksek seviyede histamin içeren balık tüketimi olduğu düşünülmektedir (Visciano ve ark., 2012). Bunun yanı sira histamin intoleransının teşhisindeki en önemli belirleyici faktörlerden birisi Çizelge 1. Histamin intoleransının semptomları (Maintz ve ark., 2006; Maintz ve Novak, 2007) yine gidalar olmaktadır (Schwelberger, 2010). Ancak histamin zehirlenmesinden sorumlu tek biyojen amin, histamin değildir, putresin ve kadaverin gibi biyojen aminler, histamini metabolize eden enzimleri metabolize ederek, histamin zehirlenmesinin etkisini arttırmaktadirlar (Karahan, 2003).

Farklı biyojen aminlerin alımları sonrasında vücuttaki biyokimyasal reaksiyonları da farklılık göstermektedir. Histamin, tiramin, putresin gibi aminler, pek çok fonksiyon açısından insanlarda pozitif şekilde kritik öneme sahip olmalarına rağmen, yüksek seviyede bulundukları gıdaların tüketimi ile toksik etki yaratabilmektedirler (Santos, 1996).

Aminler içerisinde histamin, gıda intoleransı (Fogel ve ark., 2007) ve skombroid balık zehirlenmesinin nedeni olması açısından önem taşımakta (Prester, 2011) ve histamin detoksifikasyonunun azalmasina (Hungerford, 2010) ve ayrica alerjik reaksiyonlara benzer semptomların oluşmasına sebep olmaktadır (Erol, 2007). Özellikle balık ve balık ürünlerinde uygun şartlarda işleme ve hijyen koşullarına dikkat edilmediği taktirde biyojen amin miktarında yükselme kaçınılmaz olmaktadır.

Histamin zehirlenmesi ve histamin intoleransı iki farklı olguyu tanımlamaktadır. Histamin zehirlenmesi, özellikle balık tüketimi ile ilişkilendirilen, bir biyojen amin toksisitesidir (Flick ve ark., 2001) ve yüksek seviyede histamin içeren gıdaların tüketimi ile olmaktadır. Histamin intoleransı ise diyetle alınan histamine yüksek duyarlılık gösterilmesidir (Prester, 2011).

Histamin zehirlenmesinde semptomlar, mide bulantısı, kusma, ishal, hipotansiyon, kızarıklık, ürtiker, ödem, bölgesel iltihaplar, baş ağrısı, çarpıntı, karıncalanma, cilt kızarması ve yanma şeklinde kendini göstermekte ve tedavisi anti histaminik ilaçlar kullanılarak yapılmaktadır (Flick ve ark., 2001). Yapılan bir çalışmada gıda tüketiminden sonra alerjik reaksiyonlar gösteren hastaların, gida alımının durmasıyla alerjik reaksiyonlar göstermemeleri ile kronik ürtiker rahatsızlığı, gıdalardaki biyojen aminlerin tüketimi ile ilişkilendirilmiştir (Öztürk ve ark., 2008).

Histamin toksisitesinin semptomları bozuk balığın tüketiminden sonra hızla başlamakta (genelde $30 \mathrm{dk} .-5$ sa.) ve tipik olarak 10 dakika ile 3 saat arasında devam etmektedir (Prester, 2011). Bazı vakalarda hastalık günlerce de sürebilmektedir (Lehane ve Olley, 2000). Gıdalarda bulunan biyojen aminlerin tüketimi, amin oksidaz tüketmek, gastrointestinal bir hastalığın varlığı veya alkol ya da ilaçla almak gibi faktörlerle bir araya geldiğinde daha tehlikeli olabilmektedir (Brinker ve ark., 1995). Ayrıca yüksek seviyede putresin ve spermidin varlığının, histamin ya da tiramin toksisitesini (Zarei ve ark., 2011), kadaverin varlığının da histamin toksisitesini arttırıcı etkisi olduğu bilinmektedir (Bulushi ve ark., 2009). Histamin intoleransına bağl1 semptomlar ise Çizelge 1'de gösterilmektedir. 


\begin{tabular}{ll}
\hline Organ & Semptom \\
\hline Deri & Kıarıklık, ürtiker, kaşıntı \\
\hline Gastrointestinal yol & Bulantı, kusma, abdominal ağrı, karın şişliği, ishal \\
\hline Merkezi sinir sistemi & Baş ağrısı, baş dönmesi, sersemleme \\
\hline Kardiyovasküler sistem & Hipotansiyon, taşikardi, kardiyak aritmi, anaflaksi \\
\hline Solunum sistemi & Genizde tıkanma, bronşit - solunum güçlüğü \\
\hline Ürogenital yol & Ağrılı regl oluşumu \\
\hline
\end{tabular}

Histaminin etki mekanizmas1, solunum, kardiyovasküler, gastrointestinel, hematolojik ve immünolojik sistemler ile derideki hücrelere reseptörlerini bağlaması sonucunda oluşmaktadır. Histamin zehirlenmesi sıklıkla Scomberesocidae ve Scombridae familyalarına ait skombroid balıkları ile ilişkilendirilmektedir. $\mathrm{Bu}$ familyanın balıkları, ton balığı, torik balığı, uskumru, lüfer ve zurna balığıdır. Ton balığı ve uskumru, skombroid zehirlenmesi ile en çok ilişkilendirilen iki balık olmaktadır (Flick ve ark. 2001). Bu balık türleri, kaslarındaki yüksek seviyedeki serbest histidini yayarak zehirlenmeye yol açmaktadırlar. Skombroid ailesine mensup olmayan ama zehirlenmeye sebep olan farklı türde balıklar da bulunmaktadır. Bunlar, mahimahi, sardalye, ateş balığı, hamsi, ringa, lüfer, Atlantik kılıç balığı, kızıl somon, sarıkuyruk ve kılıç balıkları şeklinde sıralanabilmektedir (Hungerford, 2010).

\section{BALIK ve ÜRÜNLERINNDE BIYYOJEN AMİN Balık}

Taze balıkta biyojen amin miktarı düşük olmakla birlikte (Petäjä ve ark., 2000; Erkan ve ark., 2006), balık, depolama ve işleme sürecinde amin oluşumu açısından hassas bir gida maddesi olarak kabul edilmektedir (Eliassen ve ark., 2002). Bu açıdan balıkta biyojen amin varlığı, bozulmanın bir göstergesi olarak indikatör görevi görmektedir (Cemek ve ark., 2006).

Balık ve ürünlerindeki biyojen amin oluşumu, direkt olarak bakteriyel üretim, aminoasit dekarboksilasyon faaliyetleri ve proteolitik aktiviteden dolayı, amino asitlerin serbest kalmasıyla başlamaktadır. Uygun çevresel koşulların varlığında bakteri gelişimi artmakta, dekarboksilaz aktivite de buna bağlı olarak gelişmektedir (Özoğul ve ark., 2004b). Hammadde ve üretim alanlarındaki hijyene önem verilmesi ile bakteriyel çoğalma ve dekarboksilaz aktivite önlenerek, amin üretiminin kontrolü gerçekleştirilmektedir (Özoğul ve ark., 2004b; Mohan ve ark., 2009).

Bakteriyel faaliyetler sonucunda balı ve ürünlerinde, başta histamin (Auerswald ve ark., 2006) olmak üzere, putresin, kadaverin, tiramin, triptamin, $\beta$ feniletilamin ve agmatin tüketiciler için risk oluşturmaktadır. Bu bağlamda çevre şartlarını bakteriyel faaliyetleri ortadan kaldıracak şekilde düzenlemek büyük önem taşımaktadır (Özoğul ve ark., 2004b). Ayrıca balıkta oluşan biyojen aminlerle, bakteriyel endotoksinler (Prester ve ark., 2009) ve balığın duyusal kalitesinin değişmesi arasında (Gökoğlu ve ark., 2004) yüksek korelasyon bulunmaktadır.
Ballk ve ürünlerinde biyojen amin oluşumunu engellemek ya da geciktirmek amaciyla yapılan en önemli işlem, üretim sürecinde hijyenik koşulların sağlanması ve sıcaklığın ayarlanması olmaktadır. Dondurma zamanı ve depolama sıcaklığı gibi faktörler histamin seviyesini etkilemektedir (Rossano ve ark., 2006). Dondurma işleminin $\left(-20^{\circ} \mathrm{C}\right)$, deniz ürünlerinde biyojen amin oluşumunu önlemede belirgin bir etkisi bulunmaktadır (Hu ve ark., 2012). Buzda depolanmış hamsinin histamin seviyesi $1,40 \pm 0,002 \mathrm{mg} / 100 \mathrm{~g}$ iken, $35{ }^{\circ} \mathrm{C}$ 'de 16 saat depolanmış hamsinin histamin seviyesi $200,70 \pm 0,94 \mathrm{mg} / 100 \mathrm{~g}$ olarak belirlenmiştir. Kadaverinde de bu değerler sırasıyla, 1,55 $\pm 0,04$ ve $86,34 \pm 0,83$ olarak tespit edilmiştir (Yongsawatdigul ve ark., 2004). Bu bağlamda biyojen amin miktarının sıcaklıkla doğrudan ilişkili olduğunu ve işleme ve depolama aşamalarında soğuk zincirin kırılıp kırılmadığına dair bir indikatör olduğunu söylemek mümkün olmaktadır.

Biyojen amin oluşumunu $4{ }^{\circ} C^{\prime}$ 'nin üzerindeki sıcaklıklar önemli ölçüde artırmaktadır (Kim ve ark., 2009). Farklı sicaklıkların biyojen amin seviyeleri üzerine etkisinin incelendiği bir çalışmada ringa balığının $2{ }^{\circ} \mathrm{C}$ (42 ppm histamin) ve $10{ }^{\circ} \mathrm{C}$ (109 ppm histamin) depolama sicaklıları arasındaki histamin seviyelerinde neredeyse üç kata yakın bir fark gözlemlenmiştir (Klausen ve Lund, 1986). Bu açıdan histamin birikimini önlemek için kullanılacak en basit metot, balığın yakalanmasından depolanmasına kadar tüm süreçlerde soğuk zincirin korunması olmaktadır (Flick ve ark., 2001; Özoğul ve ark., 2004b; FDA, 2011). Yapılan bir çalışmada, biyojen aminlerin (histamin, kadaverin, putresin ve tiramin), depolama ortamı ve soğutma koşullarının kalitesini gösteren birer indikatör oldukları belirtilmiştir. Spermin ve spermidin ise taze balıkta düşük konsantrasyonlarda bulunurken, depolama boyunca da belirgin bir değişiklik yaratmamıştır (Gökoğlu ve ark., 2004). Bu durum, iki biyojen aminin gidalarda doğal olarak bulunmaları ve bakteriyolojik faaliyetler ile oluşmamalarından kaynaklanmaktadır.

Biyojen amin oluşumu, sıcaklık ve zamana bağlı olmakla birlikte balıklarda ve deniz ürünlerinde türe özgü olarak değişmektedir (Prester ve ark., 2010). Histidince zengin (koyu kaslı) balıklarda histidince fakir (beyaz kasl1) balıklara oranla daha fazla biyojen amin oluşmaktadır (Prester ve ark., 2009). Bu bağlamda histamin, koyu renk kaslı balıkların kalite ve güvenliğinin değerlendirilmesinde temel bir indikatör olarak karşımıza çıkmaktadır. Beyaz kaslı balıklar için 
ise putresin ve kadaverin güvenli indikatörler olmaktadır (Prester, 2011). Bunu destekleyen bir çalışmada, histidince fakir olan berlam balığının depolanması sonucunda histamin oluşumunun düşük (3,08 $\mathrm{mg} / \mathrm{kg})$, buna karşıllı kadaverinin en yüksek miktardaki $(72,14 \mathrm{mg} / \mathrm{kg})$ biyojen amin olduğu tespit edilmiştir (Ruiz-Capillas ve Moral, 2001). Bir diğer çalışmada, skombroid olmayan balıklardaki aminler incelenmiş, berlam ve fener balığının farklı numunelerinde histamine rastlanmamıştır (Auerswald ve ark., 2006). Histidince zengin balıklardan, Atlantik uskumrusu ve sardalye $22{ }^{\circ} \mathrm{C}$ 'de 12 saat bekletildikten sonra balıkların histamin seviyesi insan tüketimine uygun olmayan seviyeye (50 ppm'den yüksek) ulaşmaktadır. Buna karşılık berlam balığı gibi histidince fakir balıklar daha uzun süre depolamalarda bile daha düşük histamin seviyesine sahip olmaktadırlar (Prester ve ark., 2009). Ayrica histidince zengin balıkların dondurulup, çözdürüldükten sonra oda sıcaklığında uzun süre bekletilmesi de yüksek seviyede biyojen amin sorununu beraberinde getirmektedir (Tsai ve ark., 2005a).

Sicaklık, zaman ve balığın türüne ek olarak sezon da biyojen amin miktarını etkilemektedir (Mohan ve ark., 2009). Ayrıca balığın farklı bölgelerinden alınmış numunelerinde bile 4 kata varan oranlarda değişkenlik gösteren biyojen amin miktarları tespit edilebilmektedir (Lerke ve ark., 1978). Ayrıca balığın yaşam alanı da biyojen amin oluşumunu etkilemektedir. Örneğin, sarıkuyruk balığı gibi kıyıdan açıkta yüzen balıkların, kaslarında oluşan serbest histidin miktarının artışı da histamin seviyesini arttırabilmektedir (Auerswald ve ark., 2006). Bu tip deniz ürünlerinin güvenliği, aynı zamanda, ürünün mikrobiyolojik ekolojisi, işlenme ve tüketim öncesi hazırlık işlemleri gibi faktörlerden de etkilenmektedir (Huss ve ark., 2000).

Balık filetosunun iki farklı sicaklıkta $\left(3{ }^{\circ} \mathrm{C}\right.$ ve 15 ${ }^{\circ} \mathrm{C}$ ), biyojen amin içeriğinin incelendiği bir çalışmada, sıcaklığın artması ile başta histamin olmak üzere biyojen aminlerde miktar artışı gözlemlenmiştir. $3{ }^{\circ} \mathrm{C}$ 'de 7 gün depolanan levrek filetosunda tespit edilemeyen histamin, levrek filetosu $15{ }^{\circ} \mathrm{C}$ 'de depolandığında 7 . günde $110 \mathrm{mg} / \mathrm{kg}$ miktarına kadar ulaşmıştır (Kř́ižek ve ark., 2011). Aynı çalışmada, balığa uygulanan ön işlemlerin önemi de vurgulanmıştır. Hem fileto balık hem de balık kıyması iki farklı sıcaklıkta depolanarak biyojen amin analizi gerçekleştirilmiştir. Aynı sıcaklık değerlerinde, balık kıyması, filetoya göre daha fazla biyojen amin üretmiş, bu iki değişken (sıcaklık - kıyma işlemi) içerisinde, $15{ }^{\circ} \mathrm{C}$ 'de depolanan balık kıymasının en yüksek biyojen amin seviyesine sahip olduğu tespit edilmiştir.

Sıcaklıkla birlikte biyojen amin oluşumunun hız kazandığı bilinmektedir, ancak düşük sıcaklıklarda da (4 $\left.{ }^{\circ} \mathrm{C}\right)$ biyojen amin oluşumu gerçekleşmektedir. Düşük sıcaklıklarda da duyusal kalite düşmekte, ancak yüksek sicaklıklarda $\left(20{ }^{\circ} \mathrm{C}\right)$ bu durum daha hizlı olmaktadır (Gökoğlu ve ark., 2004). Düşük sıcaklık uygulamaları, balıkların normal mikrobiyal floralarından dolayı, biyojen amin oluşumunu tam anlamiyla engelleyememektedir. Balıkların şoklanması, biyojen amin riskini tamamen ortadan kaldırmamakla birlikte, sıcaklık uygulamalarında daha etkin bir yöntem olarak karşımıza çıkmaktadır (Karahan, 2003). Balığa farklı dayandırma teknolojilerinin uygulandığı bir çalışmada, kürlenmiş sardalye, tuzlanmış ve derin dondurulmuş ringa balığı arasında biyojen amin seviyeleri açısından farklılıklar incelenmiş, derin dondurulmuş balık genel olarak tüm biyojen amin seviyelerinde en düşük değerlere sahip olarak tespit edilmiştir (Lebiedzifiska ve ark., 1991).

Ancak, balıkların dondurulup, çözdürülmesi sırasında yapılan, uzun süre oda sıcaklığında depolama ya da alet - ekipmandan kontaminasyon gibi yanlış uygulamalar da histamin oluşumu ve kalite kaybına sebep olabilmektedir (Lopez-Sabater ve ark., 1994).

Balıklardaki biyojen amin seviyesini etkileyen bir diğer faktör, balıkların işlenmeden önce içlerinin alınmamasıdır. $\mathrm{Bu}$ balıklarda intestinal mikroorganizmaların gelişimi sonucunda biyojen amin miktarı da artabilmektedir (Rossi ve ark., 2002).

Balığın raf ömrünü uzatmak amacıyla alternatif bir yöntem olarak ışınlama da kullanılmaktadır. Balık kasına uygulanan 2,5 ve $5 \mathrm{kGy}$ (İyonlaştırıcı radyasyonun maddenin birim kütlesinde soğurduğu enerji miktarı birimi) radyasyon, agmatin ve triptamin hariç diğer biyojen aminlerin seviyelerinde düşüş sağlamıştır (Özoğul ve Özden, 2013). Balıkların gama ışınlaması ile muamele edilmesiyle, 1şınlamanın, histamin seviyesinde belirgin bir düşüşe sebep olduğu, ancak kadaverin ve spermidin seviyelerine etki etmediği vurgulanmıştır (Mbarki ve ark., 2009).

\section{Fermente Balık ve Balık Sosu}

Fermente balı ürünleri, pek çok histamin zehirlenmesi vakası ile ilişkilendirilen, yüksek biyojen amin içeriğine sahip gıdalar olmaktadır (Prester, 2011). Özellikle Uzak Doğu'da yoğun olarak tüketilen balık sosu, fermente balık ürünlerinin başını çekmektedir. Balık sosu, besleyici değeri yüksek bir balık ürünüdür ancak, aynı zamanda bir biyojen amin kaynağı olarak da kabul edilmektedir (Stute ve ark., 2002). Buna rağmen, balık sosunun bir çeşni olarak yenmesi ve birden, çok yüksek miktarlarda tüketilmemesinden dolayı, biyojen aminler vücuda çok fazla alınamamakta ve bu bağlamda ürün güvenilir olarak nitelendirilebilmektedir (Zaman ve ark., 2010).

Histamin, kadaverin, putresin ve tiramin, balık sosunda en yaygın bulunan biyojen aminler olmaktadır. Ürün tipine bağlı olarak daha az miktarlarda, triptamin ve feniletilamin de bulunabilmektedir (Zaman ve ark., 2009). Fermente ve tütsülenmiş balık ürünleri ile yapılan bir çalışmada, histamin ve diğer biyojen aminlerin oluşumu arasında bir bağlantı tespit edilmemiştir (Köse ve ark., 2012). Bu ürünlerde, biyojen amin, hammaddenin kendisinden ya da 
çevreden kontamine olan halotolerant ve halofilik Enterobacteriaceae, Micrococcaceaeve laktik asit bakterilerinin aktiviteleri sonucunda oluşmaktadır (Zaman ve ark., 2009).

Balık sosunda oluşan yüksek seviyedeki biyojen amin, fermantasyon sürecinde yetersiz hijyenik koşulların göstergesi olmaktadır (Zaman ve ark., 2010). Fermantasyon boyunca kontaminasyonun önlenmesi ve fermantasyon sürecine dikkat edilmesi, daha düşük amin seviyesini sağlamaktadır (Zaman ve ark., 2009). Ayrica hammadde kalitesi ve tuzlama teknikleri (Brillantes ve ark., 2002) ve $\mathrm{pH}$, sicaklık, tuz, $\mathrm{O}_{2}$ ve şeker konsantrasyonu gibi farklı fizikokimyasal faktörler de biyojen amin oluşumunu etkilemektedir (Zaman ve ark., 2009). Yapılan bir çalışmada, fermantasyonda kullanılan suşların, biyojen amin oluşumuna önemli bir katkısı olmadığı vurgulanmıştır (Zaman ve ark., 2011). Balık sosunda biyojen amin seviyesinin azaltılması ve kontrol edilebilmesi için, bu ürünlerde, biyojen amin bir kalite kriteri olarak izlenmeli ve işletmelerin üretimlerinde sıkı hijyenik şartlar uygulanmalıdır (Jiang ve ark., 2014).

Balık sosu dışında, tuzlanıp fermente edilen balık da fermente balık ürünleri içerisinde yer almaktadır. Fermente edilmiş bu balık ürünleri ile ilgili yapılan çalışmalarda farklı oranlarda bu ürünlerin de biyojen amin içerdikleri belirtilmiştir (Mah ve ark., 2002). Tuzlanmış fermente balıkların, toplam biyojen amin miktarının depolama sürecinde 7 kat arttı̆̆ belirlenmiş ve incelenen ürünün 60 günlük depolama sürecinden sonra tehlikeli olabilecek düzeyde biyojen amin içerdiği tespit edilmiştir (Mohamed ve ark., 2009). Farklı bir çalışmada, fermente balık ürünlerine ait tüm örneklerin histamin içerdiği ve miktarının insan tüketimi için toksik doz sınırı olan 50ppm'i aşmış olduğu belirtilmiştir. Ayrıca bu ürünlerin tüketiminin skombroid zehirlenmesine yol açacağına işaret edilmiş ve bu durum hijyenik olmayan işleme koşulları ve hammadde kalitesi ile ilişkilendirilmiştir (Tsai ve ark., 2006). Ancak uygun ve hijyenik şartlarda üretilmiş, uzun depolama süreci olmaksızın tüketilen fermente balık, sağlık açısından risk oluşturmamaktadır (Ezzat ve ark., 2015).

\section{Konserve Balık}

Bir diğer önemli balık ürünü olan konserve balık üretiminde kalitesiz hammadde kullanımı, biyojen amin oluşumunun temel nedeni olmaktadır (Tsai ve ark., 2005a). Konserve ton balığ 1 örneklerinde biyojen amin analizi yapılan bir çalışmada, tüm numunelerde putresin varlığ açısından en yüksek biyojen amin, histamin $(64,61$ $\mathrm{mg} / \mathrm{kg})$, sonra sirasiyla, putresin $(10,03 \mathrm{mg} / \mathrm{kg})$, spermidin $(1,37 \mathrm{mg} / \mathrm{kg})$ ve tiramin $(0,70 \mathrm{mg} / \mathrm{kg})$ olarak tespit edilmiştir (Zarei ve ark., 2011). Aynı çalışmada histaminin tespit edildiği numunelerin \%25'inin, 50 $\mathrm{mg} / \mathrm{kg}$ kabul edilebilir histamin seviyesinden yüksek miktarda histamine sahip olduğu da bildirilmiştir.
Histamin seviyesi yükselmiş hamsi konservelerinde, tat, koku, tekstür ve renk bozuklukları da görülmektedir (Kim ve ark., 2004).

Düşük kaliteli hammadde, yanlış işleme teknikleri gibi sorunlar, konserve ürünlerinde histamin seviyesini yükseltmektedir (Zarei ve ark., 2011). Balığın işlenmesi ve depolanması sürecinde, bakteriyel faaliyet engellenmediği takdirde konserve ürünlerde de yüksek konsantrasyonlarda histamin oluşumu kaçınılmaz olmaktadır (Duyar ve Ekici, 2011).

\section{Kurutulmuş - Tütsülenmiş Balık}

Kurutulmuş balıklarda yüksek seviyede biyojen amin içerebilmektedir. Tayvan'da yapılan bir çalışmada toplanan kurutulmuş balık örneklerin \%30'u (14/46) insan tüketimine uygun doz seviyesini aşmaktadır (Huang ve ark., 2010). Tütsülenmiş somon örneklerinin 4 kGy dozda radyasyona maruz bırakıldığı başka bir çalışmada ise biyojen amin miktarında aşamalı bir düşüş gözlemlenmiştir. Ayrıca 1şınlanmış örneklerin buzdolabında depolanması sonucunda da biyojen amin oluştuğu ancak bu oluşumun 1şınlanmamış olan örneklerde daha fazla olduğu bildirilmiştir (Badr, 2012). $\mathrm{Bu}$ bağlamda balıkta biyojen amin oluşumunu geciktirici ve buna bağlı olarak kaliteyi artırıcı alternatif bir yöntem olarak radyasyon uygulamaları da önem taşımaktadır.

\section{Tuzlanmış Balık}

Tuzlama da balığ1 koruma yöntemleri arasında bulunmaktadır (Rodtong ve ark., 2005). Hafif tuzlanmış (\%1,5 tuz ya da \%1,5 tuz $+\% 1,2$ şeker) sazan üzerine yapılan bir çalışmada, tuzlama işleminin, balıkta oluşacak, fiziksel, kimyasal ve mikrobiyolojik değişimleri erteleyebileceği ve balığın duyusal özelliklerini geliştirip, raf ömrünü uzatabileceği vurgulanmıştır (Fan ve ark., 2014).

Tuzlanmış uskumrunun biyojen amin seviyesinin incelendiği başka bir çalışmada ise tüm örnekler içinde maksimum histamin seviyesi, $16,5 \mathrm{mg} / \mathrm{kg}$ olarak tespit edilmiş ve bu miktar insan tüketimi için uygun olarak değerlendirilmiştir. Ancak tuzlanmamış uskumruda biyojen amin miktarı yükselmiş ve numunelerde maksimum histamin seviyesi $39,3 \mathrm{mg} / \mathrm{kg}$ olarak tespit edilmiştir (Park ve ark., 2010). Bu durum, tuzlama işleminin biyojen amin oluşumunu engellemede etkinliğini göstermektedir. Ancak, Tayvan marketlerinden alınan tuzlanmış uskumru balıklarının incelendiği bir çalışmada, örneklerin \%6,1'inin (2/33) kabul edilebilir limitlerin üzerinde histamin içerdiği de tespit edilmiştir (Tsai ve ark., 2005b). Balığa uygulanan bu metotların etkinliği, ancak tüm aşamalarda hijyenik koşulların sağlanması ile başarılı sonuçlar verebilmektedir.

Bir diğer balık ürünü olan kızarmış balık, görece olarak güvenilir bir balık ürünü olarak kabul edilmektedir. $\mathrm{Bu}$ durum hızla işlenmesi ve günlük olarak tüketilmesi sebebiyle üründe düşük oranda 
biyojen amin oluşumundan kaynaklanmaktadır (Yeh ve ark., 2006).

Farklı balık ürünlerinin biyojen amin içeriklerinin incelendiği çalışmalarda, kürlenmiş uskumru balığı, diğer balık ürünleri ile kıyaslandığında bariz şekilde en yüksek biyojen amin seviyesine sahip ürün olmuştur (Zhai ve ark., 2012). Benzer sonuçlar farklı bir çalışmada da elde edilmiş ve kürlenmiş sardalyenin biyojen amin seviyesi, tüm örneklerde hayli yüksek olarak gözlemlenmiştir (Lebiedzifiska ve ark., 1991). Zhai ve ark. (2012)'a göre maksimum histamin seviyesi, konserve hamsi $(26,95 \mathrm{mg} / \mathrm{kg})$ ve konserve sardalyede $(22,38 \mathrm{mg} / \mathrm{kg})$ tespit edilmiş, buna karş1lık Auerswald ve ark. (2006)'a göre balık konserveleri, genel olarak düşük histamin seviyesine sahip balık ürünleri olurken, tuzlanmış ringa balığı, tütsülenmiş ıskarmoz, kurutulmuş ton balığ 1 ve balık ununda yüksek oranda histamin bulunmuştur.

\section{Modifiye Atmosferde/Vakum Paketlenmiș Balık}

Balığa uygulanan işlemler dışında, balığın duyusal özelliklerini korumak, biyojen amin oluşumunu önlemek ve kalitesi ile raf ömrünü artırmak amacıyla farklı paketleme ve depolama uygulamaları da bulunmaktadır. Hava, vakum ve modifiye atmosfer paketleme (MAP) uygulamalarında, biyojen amin seviyeleri açısından büyük farklılıklar görülmektedir. $\mathrm{CO}_{2}$, histidin dekarboksilaz aktiviteli mikroorganizmaların gelişimini inhibe ettiği için, MAP depolama, balık için uygun olmaktadır (Alak ve ark., 2011). Ancak yapılan çalışmada, taze somonun MAP altındaki bozulmasindan $P$. phosphoreum'un sorumlu mikroorganizma olduğu bildirilmiştir (Emborg ve ark., 2002).

$\mathrm{CO}_{2}$ 'le depolama, balık ürünleri için, depolama süresini en fazla uzatan uygulama olmakta ve bu ürünler için uygun sanitasyon koşulunu sağlamaktadır (Sivertsvik ve ark., 2002). Sardalyenin farklı koşullarla depolandığı bir çalışmada, en yüksek histamin seviyesi, hava ortamında, sonra sirasıyla, vakum ve modifiye atmosfer ortamında olmaktadır. Modifiye atmosferde depolama, biyojen amin seviyesi açısından en etkili sistem olup (Özogul ve Özogul, 2006), ringa balığının depolanmasında MAP'ın özellikle putresin ve kadaverin seviyelerinin düşmesinde etkisi vurgulanmaktadır (Özoğul ve ark., 2002a).

Kitosan filmlerle kaplayarak oluşturulan kombine yöntemler, güncel çalışmalar arasında yer almaktadır. MAP ve kitosan filmler ile paketleme, filetodaki Enterobacteriaceae içeriğini düşürerek, histamin oluşumunu hayli azaltmaktadır (Chong ve ark., 2011). $\mathrm{Bu}$ uygulamanın palamut filetosunda (15 gün $4{ }^{\circ} \mathrm{C}$ 'de depolanan) histamin ve kadaverin oranını önemli ölçüde düşürdüğü de belirtilmiştir (Alak ve ark., 2011).

Bir diğer ambalajlama uygulaması olan vakum paketleme, mikroorganizmalar tarafından üretilen biyojen amin gelişimini istenilen oranda önleyememektedir (Flick ve ark., 2001; Mbarki ve ark.,
2009). Yapılan bir çalışma, vakum paketlemenin düşük sıcaklıklarda depolama halinde $\left(3{ }^{\circ} \mathrm{C}\right)$ raf ömrünü 4-5 gün uzatabildiğini, ancak yüksek sicaklıklarda $\left(15^{\circ} \mathrm{C}\right)$ fark edilir bir etkisinin olmadığını ortaya koymaktadır (Křížek ve ark., 2004). Vakum ambalajlama, biyojen amin ve balık kalitesi açısından önem arz etmekle birlikte, belirleyici faktörün sıcaklık olduğunu söylemek mümkündür.

Alternatif bir uygulama olarak $\mathrm{O}_{2}$ tutan ambalajlama sistemleri de balıklar için kullanılmaktadır. $\mathrm{O}_{2}$ tutan paketler, vakum ambalajlama sistemlerine bir alternatif olarak değerlendirilmektedir. Farklı balıkların $\mathrm{O}_{2}$ 'li ve $\mathrm{O}_{2}$ tutan paketlerdeki biyojen amin seviyeleri incelenmiş ve iki paketin de biyojen amin seviyelerinde artış gözlemlenmiş, ancak $\mathrm{O}_{2}$ tutan paketlerdeki artışın daha düşük olduğu vurgulanmıştır (Mohan ve ark., 2009). $\mathrm{Bu}$ durum $\mathrm{O}_{2}$ tutan paketlerde mikroorganizma gelişiminin daha sınırlı olması ile ilişkilendirilmektedir.

Sardalyenin vakum ambalaj ve MAP koşulları altındaki histamin seviyesinin incelendiği bir çalışmada, MAP altında bulunan sardalyede bakteriyel gelişim inhibe olmuş, histamin üretimi azalmış ve raf ömrü uzamıştır. Raf ömrü vakum ambalajda 3 kata kadar uzarken bu oran MAP'ta 4 kat olarak belirlenmiştir (Özoğul ve ark., 2004a).

\section{SONUC ve ÖNERILER}

Balık ve ürünlerinde biyojen amin oluşumu, hem ürün kalitesini bozarak, tat, tekstür ve kokuyu etkilemekte, hem de tüketiciler için sağlık riskleri barındırmaktadır. Bunlara ek olarak biyojen aminler, uluslararası balık ticaretinde de önem taşımaktadır. $\mathrm{Bu}$ bağlamda balık ve ürünleri ile sıklıkla ilişkilendirilen biyojen aminler, balığın avlanmasından tüketimine kadar tüm aşamalarda takip edilerek, kontrol altına alınmalıdır.

Balık ve balık ürünlerinde biyojen amin oluşumunun en büyük etkeninin sıcaklık ve hijyen koşulları olduğu bilinmektedir. Balığı soğukta depolama ve soğuk zinciri kırmaksızın ürüne işleme ile biyojen amin seviyesi kontrol edilebilmektedir. Balığın cinsi, mikrobiyal florası ve sezon da biyojen amin seviyesini etkileyen faktörler arasında yer almaktadır.

İyi kalitede hammadde seçimi (Tsai ve ark., 2005a; Chong ve ark., 2011), HACCP (Hazard Analysis Critical Control Point), GMP (Good Manufacturing Practice), GHP (Good Hygiene Practice) gibi uygulamalarla balık ve ürünlerinin üretiminde kontaminasyonun önüne geçilerek, amin oluşumu kontrol altına alınabilmektedir (Huss ve ark., 2000; Özoğul ve ark., 2004b; Prester, 2011). Böylelikle kalite artarken, toplam kalite maliyetleri de düşmektedir (Lupin ve ark., 2010). Bu önlemlere ek olarak balıklar sürekli temiz ve soğuk yerlerde tutulmalı (Özoğul ve ark., 2004b), ayrıca balığı, steril şekilde hızla ürüne işlemek de çok önemli olmaktadır (Auerswald ve ark., 2006). Bu bağlamda balık üretiminin her aşamasında yer alan personel eğitilmeli, olası tehlikeler konusunda 
bilgilendirilmelidir. Tüketici de bu zincirin bir parçası olarak, balık ve ürünlerini tüketme ve saklama koşulları hakkında bilinçlendirilmelidir.

Büyük balıkların depolanması, depolama sistemindeki arızalar, depoların aşırı yüklenmesi ya da soğutmayı engelleyici faktörler, hızla biyojen amin seviyesinin yükselmesine sebep olmaktadır (Lerke ve ark., 1978). Bu faktörler de sürekli takip edilerek, balık her aşamada kontrol edilmelidir.

Biyojen aminlerin toksisiteye sebep olması bakımından teşhis ve tedavisi çalışmaları üzerine durulmalıdır. Toksik etki oluşuran ürünler tespit edildikten sonra geriye doğru izlenerek, sebep olan balık ve üretim süreçleri takip edilmeli ve gerekli iyileştirmeler yapılmalıdır. Balık endüstrisinde kontaminasyon konusunda önlemler alınmalı, sik1 hijyenik şartlar sağlanmalı ve denetimleri gerçekleştirilmelidir.

Işınlama, kitosan filmlerle kaplama gibi biyojen amin miktarını düşüren alternatif yöntemler geliştirilmeli. En uygun yöntemler ya da kombinasyonları tespit edilerek balı endüstrisinde kullanımları sağlanmalıdır.

\section{KAYNAKLAR}

Alak, G., Hisar, S. A., Hisar, O., Genççelep, H. 2011. Biogenic amines formation Atlantic bonito (Sarda sarda) fillets packaged with modified atmosphere and vacuum wrapped in chitosan and cling film at 4 ${ }^{\circ} \mathrm{C}$. Eur. Food Res. Technol., 232: 23-28.

Auerswald, L., Morren, C., Lopata, A. L. 2006. Histamine levels in seventeen species of fresh and processed South African seafood. Food Chemistry, 98: 231-239.

Badr, H. M. 2012. Control of the potential health hazards of smoked fish by gamma irradiation. International Journal of Food Microbiology, 154: 177-186.

Bardocz, S. 1995. Polyamines in food and their consequences for food quality and human health. Trencls in Food Science \& Technologgy, 6: 341346.

Bover-Cida, S., Holzapfel, W. H. 1999. Improved screening procedure for biogenic amine production by lactic acid bacteria. International Journal of Food Microbiology, 53: 33-41.

Brillantes, S., Paknoi, S., Totakien, A. 2002. Histamine Formation in Fish Sauce Production. Journal of Food Science, 67(6): 2090-2094.

Brink, B. J., C. Damink, H. M. L. J. Joosten,. J. H. J. Huis in't Veld, 1990. Occurence and formation of biologically active amines in foods. Int. J. Food Microbiol., 11: 73-84.

Brinker, C. D., Kerr, M., Rayner, C. 1995. Investigation Of Biogenic Amines in Fish and Fish Products. Victoria: Public Health Division Victorian Government Department of Human Services.
Bulushi, I. A., Poole, S., Deeth, H. C. 2009. Biogenic Amines in Fish: Roles in Intoxication, Spoilage, and Nitrosamine Formation.-A Review. Critical Reviews in Food Science and Nutrition, 49: 369-377.

Cemek, M., Bulut, S., Konuk, M., Akkaya, L., Birdane, Y., Yılmaz, E. 2006. Eber ve Karamık Göllerinden Avlanan Sazan (Cyprinus carpio) ve Turna (Esox lucius) Balıklarında Depolama Sicaklığı ve Süresinin Biyojen Amin Oluşumuna Etkisi. Gıda Teknolojileri Elektronik Dergisi, (1): 27-34.

Chong, C. Y., Abu Bakar, F., Russly, A. R., Jamilah, B., Mahyudin, N. A. 2011. The effects of food processing on biogenic amines formation. International Food Research Journal, 18(3): 867876.

Dapkeviciusa, M. L., Nouta, M. R., Romboutsa, F. M., Houben, J. H., Wymenga, W. 2000. Biogenic amine formation and degradation by potential fish silage starter microorganisms. International Journal of Food Microbiology, 57: 107-114.

Demirci, M. 2003. Gıda Kimyası. Tekirdağ: Rebel Yayıncılık.

Duyar, H. A., Ekici, K. 2011. Balık Konservelerinde Histamin ve $\mathrm{pH}$ Düzeylerinin Belirlenmesi Üzerine Bir Çalışma. YYU. Veteriner Fakultesi Dergisi, 22(2): 71-74.

Eliassen, K. A., Reistad, R., Risøen, U., Rønning, H. F. 2002. Dietary polyamines. Food Chemistry, 78: 273-280.

Emborg, J., Laursen, B., Rathjen, T., Dalgaard, P. 2002. Microbial spoilage and formation of biogenic amines in fresh and thawed modified atmospherepacked salmon (Salmo salar) at $2^{\circ} \mathrm{C}$. Journal of Applied Microbiology, 92: 790-799.

Erkan, N., Özden, Ö., Alakavuk, D. Ü., Yildirim, Ş. Y., İnuğur, M. 2006. Spoilage and shelf life of sardines (Sardina pilchardus) packed in modified atmosphere. Eur. Food Res. Technol., 222: 667-673.

Erol, İ. 2007. Gıda Hijyeni ve Mikrobiyolojisi. Pozitif Matbaacılık Ltd. Şti. Ankara.

Ezzat, M., Zare, D., Karim, R., Ghazali, H. 2015. Transand cis-urocanic acid, biogenic amine and amino acid contents in ikan pekasam (fermented fish) produced from Javanese carp (Puntius gonionotus) and black tilapia (Oreochromis mossambicus). Food Chemistry, 172: 893-899.

Fan, H., Luo, Y., Yin, X., Bao, Y., Feng, L. 2014. Biogenic amine and quality changes in lightly saltand sugar-salted black carp (Mylopharyngodon piceus) fillets stored at $4{ }^{\circ} \mathrm{C}$. Food Chemistry, 159: 20-28.

FDA (Food and Drug Administration), 2011. Fish and Fishery Products Hazards and Controls Guidance. Department of Health And Human Services Public Health Service Food And Drug Administration Center For Food Safety And Applied Nutrition Office of Food Safety. 
Flick, G. J., Oria, M. P., Douglas, L. 2001. Potential Hazards in Cold-Smoked Fish: Biogenic Amines. Special Supplement to the Journal of Food Science, 66(7): 1088-1099.

Fogel, W., Lewinski, A., Jochem, J. 2007. Histamine in food: is there anything to worry about? Biochemical Society Transactions, 35(2): 349-352.

Gardinia, F., Martuscelli, M., Caruso, M. C., Galgano, F., Crudele, M. A., Favati, F., et al. 2001. Effects of $\mathrm{pH}$, temperature and $\mathrm{NaCl}$ concentration on the growth kinetics, proteolytic activity and biogenic amine production of Enterococcus faecalis. International Journal of Food Microbiology, 64: 105-117.

Gökoğlu, N., Yerlikaya, P., Cengiz, E. 2004. Changes in Biogenic Amine Contents And Sensory Quality of Sardine (Sardina Pilchardus) Stored At $4{ }^{\circ} \mathrm{C}$ And 20 ${ }^{\circ} \mathrm{C}$. Journal of Food Quality, 27: 221-231.

Hu, Y., Huang, Z., Li, J., Yang, H. 2012 Concentrations of biogenic amines in fish, squid and octopus and their changes during storage. Food Chemistry, 135: 2604-2611.

Huang, Y.-R., Liu, K.-J., Hsieh, H.-S., Hsieh, C.-H., Hwang, D.-F., Tsai, Y.-H. 2010. Histamine level and histamine-forming bacteria in dried fish products sold in Penghu Island of Taiwan. Food Control, 21: 1234-1239.

Hungerford, J. M. 2010. Scombroid poisoning: A review. Toxicon, 56: 231-243.

Huss, H. H., Reilly, A., Embarek, P. K. 2000. Prevention and control of hazards in seafood. Food Control, 11: 149-156.

Jiang, W., Xu, Y., Li, C., Dong, X., Wang, D. 2014 Biogenic amines in commercially produced Yulu, a Chinese fermented fish sauce. Food Additives \& Contaminants: Part B, 7(1): 25-29.

Kalac, P., Krausova, P. 2005. A review of dietary polyamines: Formation, implications forgrowth and health and occurrence in foods. Food Chemistry, 90: 219-230.

Karahan, A. G. 2003. Gidalarda Biyojen Aminler. Orlab On-Line Mikrobiyoloji Dergisi, 1(5): 21-32.

Kim, M.-K., Mah, J.-H., Hwang, H.-J. 2009. Biogenic amine formation and bacterial contribution in fish, squid and shellfish. Food Chemistry, 116: 87-95.

Kim, S. H., Eun, J. B., Chen, T. Y., Wei, C. I., Clemens, R. A., An, H. 2004. Evaluation of Histamine and Other Biogenic Amines and Bacterial Isolation in Canned Anchovies Recalled by the USFDA. Journal of Food Science, 69(6): 157-162.

Klausen, N. K., Lund, E. 1986. Formation of biogenic amines in herring and mackerel. Z Lebensm Unters Forsch, 182: 459-463.

Köse, S., Koral, S., Tufan, B., Pompe, M., Scavniçar, A., Koçar, D. 2012. Biogenic amine contents of commercially processed traditional fish products originating from European countries and Turkey. Eur Food Res Technol, 235: 669-683.
Křížek, M., Vácha, F., Vejsada, P., Pelikánová, T. 2011. Formation of biogenic amines in fillets and minced flesh of three freshwater fish species stored at $3{ }^{\circ} \mathrm{C}$ and $15{ }^{\circ} \mathrm{C}$. Acta Vet. Brno, 80: 365-372.

Krrížek, M., Vácha, F., Vorlova, L., Lukasova, J., Cupakova, S. 2004. Biogenic amines in vacuumpacked and non-vacuum-packed flesh of carp (Cyprinus carpio) stored at different temperatures. Food Chemistry, (88): 185-191.

Lebiedzifiska, A., Lamparczyk, H., Ganowiak, Z., Eller, K. I. 1991. Differences in biogenic amine patterns in fish obtained from commercial sources. Z Lebensm Unters Forsch, 192: 240-243.

Lehane, L., Olley, J. 2000. Histamine fish poisoning revisited. International Journal of Food Microbiology, 58: 1-37.

Lerke, P. A., Werner, S. B., Taylor, S. L., Linda S. Guthertz. 1978. Scombroid Poisoning Report of an Outbreak. West J. Med, 129: 381-386.

Lopez-Sabater, Emilio I., Rodriguez-Jerez, Jose J., Roig-Sagues, Artur X., Mora Ventura, M.A. Teresa. 1994. Bacteriological Quality of Tuna Fish (Thunnus thynnus) Destined for Canning: Effect of Tuna Handling on Presence of Histidine Decarboxilase Bacteria and Histamine Level. Journal of Foof Protection, 57: 318-323.

Lupin, H., Parin, M., Zugarramurdi, A. 2010. HACCP economics in fish processing plants. Food Control, 21: 1143-1149.

Mah, J.-H., Han, H.-K., Oh, Y.-J., Kim, M.-G., Hwang, H.-J. 2002. Biogenic amines in Jeotkals, Korean salted and fermented fish products. Food Chemistry, 79: 239-243.

Maintz, L., Novak, N. 2007. Histamine and histamine intolerance. Am J Clin Nutr, 85: 1185-96.

Maintz, L., Bieber, T., Novak, N. 2006. Histamine Intolerance in Clinical Practice. Dtsch Arztebl, 103(51-52): 3477-3483.

Mbarki, R., Miloud, N. B., Selmi, S., Dhib, S., Sadok, S. 2009. Effect of vacuum packaging and low-dose irradiation on the microbial, chemical and sensory characteristics of chub mackerel (Scomber japonicus). Food Microbiology, 26: 821-826.

Mohamed, R., Livia, S.-S., Hassan, S., Soher, E.-s., Ahmed-Adel, E. B. 2009. Changes in free amino acids and biogenic amines of Egyptian saltedfermented fish (Feseekh) during ripening and storage. Food Chemistry, 115: 635-638.

Mohan, C., Ravishankar, C., Gopal, T. S., Kumar, K. A., Lalitha, K. 2009. Biogenic amines formation in seer fish (Scomberomorus commerson) steaks packed with $\mathrm{O}_{2}$ scavenger during chilled storage. Food Research International, 42: 411-416.

Önal, A. 2007. A review: Current analytical methods for the determination of biogenic amines in foods. Food Chemistry, 103: 1475-1486.

Özogul, F., Özden, Ö. 2013. The Effects of Gamma Irradiation on the Biogenic Amine Formation in Sea 
Bream (Sparus aurata) Stored in Ice. Food Bioprocess Technol, 6: 1343-1349.

Özogul, F., Özogul, Y. 2006. Biogenic amine content and biogenic amine quality indices of sardines (Sardina pilchardus) stored in modified atmosphere packaging and vacuum packaging. Food Chemistry, 99: 574-578.

Özogul, F., Polat, A., Özogul, Y. 2004a. The effects of modified atmosphere packaging and vacuum packaging on chemical, sensory and microbiological changes of sardines (Sardina pilchardus). Food Chemistry, 85: 49-57.

Özogul, F., Taylor, K. D., Quantick, P., Özogul, Y. 2002a. Biogenic amines formation in Atlantic herring (Clupea harengus) stored under modified atmosphere packaging using a rapid HPLC method. International Journal of Food Science and Technology, 37: 515-522.

Özogul, F., Taylor, K., Quantıck, P., Özogul, Y. 2002b. Changes in Biogenic Amines in Herring Stored under Modified Atmosphere and Vacuum Pack. Journal of Food Science, 67(7): 2497-2501.

Özoğul, F., Küley, E., Özoğul, Y. 2004b. Balık ve Balık Ürünlerinde Oluşan Biyojenik Aminler. E.Ü. Su Ürünleri Dergisi, 21(3-4): 375-381.

Öztürk, S., Çalışkaner, Z., Güleç, M., Göçgeldi, E., Kutlu, A. 2008. Kronik ürtiker ve anjioödemde biyojenik aminlerin rolü. Tıp Araştırmaları Dergisi, 6(3) :163 -167.

Paleologos, E., Savvaidis, I., Kontominas, M. 2004. Biogenic amines formation and its relation to microbiological and sensory attributes in ice-stored whole, gutted and filleted Mediterranean Sea bass (Dicentrarchus labrax). Food Microbiology, 21: 549-557.

Park, J. S., Lee, C. H., Kwon, E. Y., Lee, H. J., Kim, J. Y., Kim, S. H. 2010. Monitoring the contents of biogenic amines in fish and fish products consumed in Korea. Food Control, 21: 1219-1226.

Petäjä, E., Eerola, S., Petäjä, P. 2000. Biogenic amines in cold-smoked fish fermented with lactic acid bacteria. Eur. Food Res. Technol, 210: 280-285.

Prester, L. 2011. Biogenic amines in fish, fish products and shellfish: a review. Food Additives and Contaminants, 28(11): 1547-1560.

Prester, L., Macan, J., Varnai, V. M., Orct, T., Vukušıć, J., Kıpčıć, D. 2009. Endotoxin and biogenic amine levels in Atlantic mackerel (Scomber scombrus), sardine (Sardina pilchardus) and Mediterranean hake (Merluccius merluccius) stored at $22{ }^{\circ} \mathrm{C}$. Food Additives and Contaminants, 26(3): 355-362.

Prester, L., Orct, T., Macan, J., Vukušıć, J., Kıpčić, D. 2010. Determination of Biogenic Amines and Endotoxin In Squid, Musky Octopus, Norway Lobster, and Mussel Stored At Room Temperature . Arh Hig Rada Toksikol, 61: 389-397.

Rodtong, S., Nawong, S., Yongsawatdigul, J. 2005. Histamine accumulation and histamine-forming bacteria in Indian anchovy (Stolephorus indicus). Food Microbiology, 22: 475-482.

Rossano, R., Mastrangelo, L., Ungaro, N., Riccio, P. 2006. Influence of storage temperature and freezing time on histamine level in the European anchovy Engraulis encrasicholus (L., 1758): A study by capillary electrophoresis. Journal of Chromatography B,, 830: 161-164.

Rossi, S., Lee, C., Ellis, P., Pivarnik, L. 2002. Biogenic Amines Formation in Bigeye Tuna Steaks and Whole Skipjack Tuna. Journal of Food Science, 67(6): 2056-2060.

Ruiz-Capillas, C., Moral, A. 2001. Production of Biogenic Amines and Their Potential Use as Quality Control Indices for Hake (Merluccius merluccius, L.) Stored in Ice. Journal of Food Science, 66(7): 1030-1032.

Santos, M. S. (1996). Biogenic amines: their importance in foods. International Journal of Food Microbiology, 29: 213-231.

Schwelberger, H. G. 2010. Histamine intolerance: a metabolic disease? Inflamm. Res., 59(2): 219-221.

Shalaby, A. R. 1996. Significance of biogenic amines to food safety and human health. Food Research International, 29(7): 675-690.

Sivertsvik, M., Jeksrud, W. K., Rosnes, J. T. 2002. A review of modified atmosphere packaging of fish and fishery products - significance of microbial growth, activities and safety. International Journal of Food Science and Technology, 37: 107-127.

Stute, R., Petridis, K., Steinhart, H., Biernoth, G. 2002. Biogenic amines in fish and soy sauces. Eur. Food Res. Technol., 215: 101-107.

Tsai, Y.-H., Kung, H.-F., Lee, T.-M., Chen, H.-C., Chou, S.-S., Wei, C.-I., et al. 2005a. Determination of histamine in canned mackerel implicated in a food borne poisoning. Food Control, 16: 579-585.

Tsai, Y.-H., Lin, C.-Y., Chang, S.-C., Chen, H.-C., Kung, H.-F., Wei, C.-I., et al. 2005b. Occurrence of histamine and histamine-forming bacteria in salted mackerel in Taiwan. Food Microbiology, 22: 461467.

Tsai, Y.-H., Lin, C.-Y., Chien, L.-T., Lee, T.-M., Wei, C.-I., Hwang, D.-F. 2006. Histamine contents of fermented fish products in Taiwan and isolation of histamine-forming bacteria. Food Chemistry, 98: 64-70.

Visciano, P., Schirone, M., Tofalo, R., Suzzi, G. 2012. Biogenic amines in raw and processed seafood. Frontiers in Microbiology, 3(188): 1-10.

Yeh, C.-Y., Lin, S.-J., Hwang, D.-F. 2006. Biogenic amines, histamine and label of dressed fried fish meat products in Taiwan. Food Control, 17: 423428.

Yongsawatdigul, J., Choi, Y., Udomporn, S. 2004. Biogenic Amines Formation in Fish Sauce Prepared from Fresh and Temperature abused Indian Anchovy 
(Stolephorus indicus). Journal of Food Science, 69(4): 312-319.

Zaman, M. Z., Abdulamir, A., Bakar, F. A., Selamat, J., Bakar, J. 2009. A Review: Microbiological, Physicochemical and Health Impact of High Level of Biogenic Amines in Fish Sauce. American Journal of Applied Sciences, 6(6): 1199-1211.

Zaman, M. Z., Bakar, F. A., Jinap, S., Bakar, J. 2011. Novel starter cultures to inhibit biogenic amines accumulation during fish sauce fermentation. International Journal of Food Microbiology, 145: 84-91.

Zaman, M. Z., Bakar, F. A., Selamat, J., Bakar, J. 2010. Occurrence of Biogenic Amines and Amines
Degrading Bacteria in Fish Sauce. Czech J. Food Sci, 28(5): 440-449.

Zarei, M., Najafzadeh, H., Enayati, A., Pashmforoush, M. 2011. Biogenic Amines Content of Canned Tuna Fish Marketed in Iran. American-Eurasian Journal of Toxicological Sciences, 3(3): 190-193.

Zhai, H., Yang, X., Li, L., Xia, G., Cen, J., Huang, H., et al. 2012. Biogenic amines in commercial fish and fish products sold in southern China. Food Control, 25: 303-308. 